The original publication is available at www.springerlink.com:

Labusch, N., Winter, R.: Method Support of Large-Scale Transformation in the Insurance Sector: Exploring Foundations, Aier, S., Ekstedt, M., Matthes, F., Proper, E., Sanz, J. (Eds.): Trends in Enterprise Architecture Research and Practice Driven Research on Enterprise Transformation, Barcelona, 23.10.2012, Springer, Berlin, Heidelberg, LNBIP 131, 2012, pp. 60-78. DOI: 10.1007/978-3-642-34163-2_4

\title{
Method Support of Large-Scale Transformation in the Insurance Sector: Exploring Foundations
}

\author{
Nils Labusch, Robert Winter \\ Institute of Information Management, University of St. Gallen, Mueller-Friedberg-Strasse 8, \\ 9000 St. Gallen, Switzerland \\ \{Nils Labusch, Robert.Winter\}eunisg.ch
}

\begin{abstract}
Many enterprises need to handle programs that impose fundamental changes to the organization as well as the supporting IT systems. While general guidance for such transformations in form of methods, reference models, principles, etc. is available, the specific context of the insurance sector is often not considered. We conducted an interview series with informants from major European insurance companies to explore the specifics of enterprise transformation in the insurance sector. The results suggest amending existing transformation support methods by regarding transformation triggers, transformation program types and core techniques. E.g., transformations that deal with standardization, mergers and acquisitions and internal alignment are not sufficiently covered yet and techniques that deal with soft and social aspects of transformations are less visible in the insurance sector. Our findings create not only the basis for a wider survey to extend and validate initial findings, but also for comparing and discussing concrete enterprise transformation cases.
\end{abstract}

Keywords: transformation, insurance, techniques, method, empirical study

\section{Introduction}

Enterprises need to pass through major transformations. Rouse [1] defines such enterprise transformation (ET) not as routine but "fundamental change that substantially alters an organization's relationships with one or more key constituencies, e.g., customers, employees, suppliers, and investors". ET can involve new value propositions (like products and services) or change the inner structure of the enterprise. Further, ET could involve old value propositions provided in fundamentally new ways [1]. Examples are mergers $\&$ acquisitions, detachment of host systems or other efforts that are reflected in strategic planning. Unfortunately, many ETs are not or only partially successful, often because enterprises do not maintain an appropriate transformation capability [2].

The insurance sector is affected by major ETs only recently. In the past, the business model in the sector was very stable [3]. This changed in recent years: ET is induced by changing legislation and regulation (e.g. the Solvency act) [4] as much as increasing cost pressure e.g. induced by the changing situation on the financial markets and the financial crisis. The context of the ETs is difficult for manifold 
reasons. First, the inner culture of the insurances is rather traditional - major ETs were not necessary in the past. Second, contracts with customers need to be kept and managed for long periods, even longer than those of banks. This leads e.g. to IT systems that are sometimes many decades in use [5]. Third, national differences need to be considered. On the one hand, the legislation differs, on the other hand market structure and customer demands force the insurance companies to strive away from their traditional business models [3].

In order to deal with these challenges, sound methods can provide guidance and avoid major and expensive failure. Incorporating the industry context proved already valuable to be in other related areas [6] and methods [7]. In order to develop these methods, it is important to understand, which techniques (thus, possible ways in which the results e.g. the successful ET can be achieved [8]) are necessary or effective in a certain situation. We concentrate on techniques in the paper at hand, since many of these are already existent in the companies (examples are techniques also applied in program management, like goal definition or milestone planning) and guidance about which techniques to concentrate on during the ET. Because of the complexity of the ET, single solutions cannot be expected to fit all problems, the design and engineering of guidance however needs to consider the specifics of the current problem [9]. As a compromise between (economic) 'one size-fits-all' solutions and (most effective) problem-specific ones, usually a handful of problem situations are differentiated that cluster related design problems [10]. These situations are usually specified by a combination of context factors (e.g. size of the industry) with certain program types [8]. Depending on the situation, different techniques might be appropriate in order to handle the specific situation.

Because of the specific products, services and the induced challenges and goals in the insurance market that differ from other industries, we assume that effective ET guidance needs to include assistance about where to focus on during an ET. Therefore, in order to provide ET guidance for the insurance industry, we need to investigate the detailed context of the industry and triggers that imply certain types of ET. Further we need to know which techniques are necessary or obligatory in order to conduct successful ET programs in this industry sector. This paper aims at exploring the insurance setting and the identification of aspects that differ from generic ET guidance. Thus we propose the following research question:

RQ: What are context, triggers, program types, core techniques of enterprise transformation in the insurance sector?

We discuss the related work in section two. We go on by presenting our research approach in section three. The results are presented in section four and summarizing propositions are drawn. In section five we discuss these propositions and their influence on the guidance of ET in the insurance sector. Section six provides a summary and outlook. 


\section{Method Support of Large-Scale Transformation in the Insurance Sector: Exploring}

Foundations 3

\section{Related Work}

Manifold methods and approaches to deal with fundamental changes in organizations have been proposed. We conducted a literature database search including for-and backward search in order to identify approaches that concentrate on fundamentally changing the business and less on an optimization of the day-to-day activities. Findings reveal approaches like total quality management (TQM) which gained attention almost 20 years ago, focusing on aspects like quality awareness, continuous improvement, quality measuring and control [11]. A more recent approach is Six Sigma, a method that deals with the improvement of processes in organizations [12]. However, these approaches focus on continuous improvement and do not include specific techniques relevant for ETs. Six Sigma further is related to industrial application and thus less appropriate for the insurance context [13].

Relevant findings that concentrate on fundamental changes and thus ET are rare. One approach that we identified is the business engineering framework by Oesterle \& Winter [14] which proposes the identification of drivers and goals of ETs by explicitly including business as much as IT-related aspects. A more recent approach proposed by SAP is Business Transformation Management Methodology $\left(\mathrm{BTM}^{2}\right)-\mathrm{a}$ practice driven approach that includes well-known disciplines like strategic management, process management project and portfolio management which are integrated by means of an additional discipline called meta management [15]. Such meta-management offers a cyclic and iterative phase model for ETs (envision, engage, transform and optimize), a structure including roles and activities, provision of measures, skill development support and principles to conduct ET programs. However, the approach does not provide context-oriented guidance like industry specific extensions for the insurance sector.

Another approach is introduced by Baumoel [16, 17]. The author developed a situational method to support ET programs. The approach is based on interviews with informants from different industries, case studies with heterogeneous types of ETs and the analysis of ET-related methods. The approach aims at investigating which techniques were successfully applied in specific situations of ET. In order to identify the specific situations, a list of influence factors was created. Such influence factors for example are the process architecture, the available capabilities, the structure of competition, power structures, existing measures and many more. The analyzed cases are clustered according to these influence factors into five clusters of ET situations: "strategy adaptation", "communication and interaction with customers and business network", "growth strategies and cultural aspects in a technological context", "process engineering and process redesign" and "improvement of agility of the organization". In the next step, the author analyzes whether there is a systematic relationship between the successful application of certain techniques and the ET situation. The analysis yields some techniques that have been successfully applied in every ET, no matter which specific situation is present, while some other techniques have been successfully applied only in specific ET situations. Figure 1 illustrates the concept of situation specific technique application. 


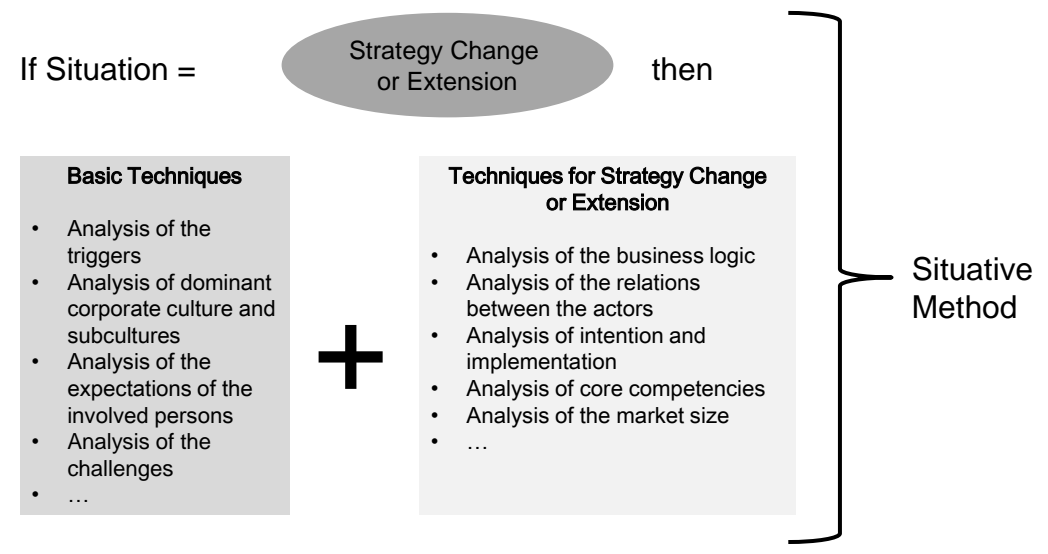

Fig. 1. Basic Concept of the Baumoel Approach (based on $[16,17]$ )

Once a situation is identified (e.g. "Strategy Change or Extension"), Baumoel's method provides guidance on how to deal with such an ET program. This especially includes a list of techniques that should be applied because these techniques have been successfully applied in "similar" ETs, i.e. in the same ET situation. In a concrete ET, the identification of the respective situation together with the choice of appropriate (= generally applicable plus situation specific) techniques constitute a situational ET support method.

Baumoel's approach provides some insights that provide a starting point regarding our research question. It is designed however to deal with ET in general. The underlying interviews and cases were conducted in many industries; the coverage of insurance companies remains unclear.

While Baumoel's approach focuses on the techniques applied during an ET, other approaches focus on capabilities [18], roles of individuals or corporate functions [19, 20] or governance structures [21]. From our point of view, all of them are important since we share the understanding of Purchase et al. [22] who consider the ET activities as occurring in a complex system environment. Each of these perspectives on ET therefore presents an important aspect that together support a holistic view on ET. However, in this paper we narrow down the focus on the techniques perspective for the following reason: Staw \& Epstein [23] discuss the impact of different techniques on the firms performance. While not finding a significant influence in the industrial context, Iseri-Say et al. [24] identify positive influences in the context of a more heterogeneous industry mix (e.g. service and production sector). They further show how single techniques differ in their positive business impact. This provides evidence for the importance of the industry sector and motivates the focus on techniques as a general managerial value driver.

Summarized, related work implies that (1) ET is a complex challenge that needs guidance, e.g. by method support, (2) the existing approaches differ in their degree of detail according to the described techniques and situations, and (3) applying such an approach yields techniques that are most relevant in certain situations. Although these findings are widely accepted, some issues for insurance companies remain: None of 


\section{Method Support of Large-Scale Transformation in the Insurance Sector: Exploring}

Foundations 5

the discussed approaches explicitly covers the insurance industry at this time. Therefore, the specific detailed context of this sector as well as specific ET situations that exist (only) in this sector are not covered by existing work. The identification of specific context, specific triggers, specific ET situations and respective techniques of ET in the insurance sector is yet to be undertaken - we prepare to fill this gap by exploring the field in a first step.

\section{Research Approach}

Given the limited existing guidance for ET in the insurance sector, we used the approach introduced by Baumoel [16] as a foundation for our work. The reason is the solid base with identified techniques, program types and the empirical foundation. We conducted a multiple case study approach guided by Eisenhardt [25]. Such an approach usually yields robust and generalizable findings [26].

\subsection{Data Collection in Literature \& Interviews}

In order to gain detailed insight to the context in the insurance industry we conducted literature search by following guidance provided e.g. by vom Brocke et al. [27] and Webster \& Watson [28]. Since we wanted to identify as many ET triggers and context factors ahead of the interview phase, we conducted a general database search and did not restrict this search by concentrating on major journals or conferences. However, we restricted the search by filtering research areas in order to keep the focus on the guiding research question (e.g. we excluded medical articles). We further aimed at the identification of case studies related to the topic. We applied the following search terms:

- "Insurance Industry" AND (Challenge* OR defiance*)

- Transform AND "insurance industry"

- Change AND insurance

- $\quad$ Topic $=($ "case study") AND Topic $=($ change $)$ AND Topic $=($ insurance $)$

- Topic $=($ "case study") AND Topic $=($ transform* $)$ AND Topic $=($ insurance $)$

We surveyed the results by reading the abstracts and finalizing the decision if an article was relevant for further inclusion in the research process. We decided to only include articles that deal with ET in the insurance context or such that provide probably relevant context factors. In addition to the structured search, we conducted reverse searches by surveying the references of articles we found during the first search steps. We further added sources that were already known in the research group in order to provide a rich foundation for the preparation of the interviews.

Based on the surveyed literature, we developed the questionnaire for the interviews. The questionnaire starts with biographical questions about the company and the informant's role in that company. We move on with open questions about the market environment of the company (like "Are there dominant strategies that 
insurance companies execute?). We move on to open, ET related questions (e.g. "If you compare different ET programs, what is important to achieve success?"). We asked the interviewee to think about concrete ET programs he/she is part of and to illustrate these. We related the following questions to these examples in order to allow for a court-room questioning style of interviewing [29]. We asked primarily about the extent, the scope and the success of the ET in the following part of the questionnaire. We further asked for situations by providing and discussing five reference situations based on Baumoel $[16,17]$ that we slightly modified (concerning the wording) in order to increase their understandability and relevance for the insurance industry. We ended the questionnaire with closed questions like ("Which of those techniques have been necessary in order to be successful in the ET?"). We provided a list of techniques, also based on Baumoel $[16,17]$ that according to the method are always necessary to be conducted (basic class). We discussed with the interview partners if this is the case or if ET programs have been successful even without considering those techniques.

We conducted the interviews face-to-face or via telephone, depending on the availability of the interviewees or the local distance. For the phone interviews we incorporated guidelines given by Burke \& Miller [30] like providing the questionnaire upfront or being aware of the difficulties of the communication channel. We relied on additional data sources like reports offered by the insurances (e.g. the annual reports), publically available information about the interviewees (e.g. social network profiles), press releases, websites, field notes etc. The triangulation of such sources increases the robustness of the resulting findings [31]. Our informants were all highly knowledgeable managers or C-level assistants. We used snowball sampling [32] in order to get in contact with further interview partners in the same case company (thus, we included the question "Do you know colleagues that could provide insight to this topic?"). All interviews were recorded and transcribed in order to allow for further processing by different researchers. We transcribed the interview in the language we discussed with participants. Extracts presented in this paper are translated for understandability reasons. Some informants did not allow full transcripts but only summaries of the interviews. In order to avoid biases of informants, whenever possible we interviewed more than one person for each case. We asked the informants to focus on their own experiences and tried to find examples that are not located too far away in the past. We further tried to avoid questioning that allows informants to speculate [19]. We further promised our informants to keep their and their company`s anonymity in order to allow them for providing honest answers.

\subsection{Informants}

Our informants are working with three European insurance companies that provide life and non-life insurance for private and business customers. All informants are located in departments that allow for a broad overview of the programs and programs executed and those that belong to ETs. Our informant from INSURANCE1 conducted large-scale IT programs, before changing to the business side of the insurance. Our informant from INSURANCE2 is mostly dealing with transformations from a 
financial point of view. The informants from INSURANCE3 are located in the Clevel offices related to IT (INSURANCE3a) or business operations (INSURANCE3b).

\subsection{Data Analysis}

We followed recommendations for multiple case studies by Eisenhardt [25] and used within-case and cross case analysis. We used the software Atlas.Ti in order to conduct a first open coding. We used the graphical functions of Atlas.Ti in order to cluster the codes in a purposeful way to get an overview concerning the constructs we were searching for. We used cross-case analysis for the following purposes: First, we aksed our informants about their experience concerning triggers of certain program types. By comparing the answers of different informants, we could combine those into a mapping. Second, we compared the informant's perceptions about the value and necessity of certain techniques we provided them with.

\section{Findings}

In this section we provide our findings from literature search and case interviews. We especially present triggers for ET programs, context factors, classes of ET programs and techniques concerning the insurance industry.

\subsection{Triggers for Enterprise Transformations}

The literature analysis revealed several potential driving factors for ET programs. Especially a large-scale study by Fuernthaler et al. [3] provided challenges in the insurance industry that we interpreted as potential ET triggers. However, in the cases we asked the informants about their perception of triggering factors. We could relate most of them to the identified potential factors of the literature analysis. Table 1 provides evidence for the relevant drivers for ET programs. 
Table 1. Potential Trigger for ETs in the Insurance Sector

\begin{tabular}{|c|c|c|}
\hline & Evidence Literature & Evidence Case Studies \\
\hline 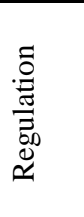 & Regulation $[3,4]$ & $\begin{array}{l}\text { "There is the whole insurance contract legislation, } \\
\text { the small revision. Right now that is in parliament } \\
\text { and will for sure affect us." (INSURANCE1). } \\
\text { Legislation imposes changes to the insurances un } \\
\text { strategic and operational level (INSURANCE2). }\end{array}$ \\
\hline \multirow{2}{*}{ 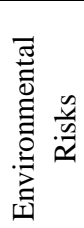 } & $\begin{array}{l}\text { Climate change fosters } \\
\text { risks }[33,34]\end{array}$ & \\
\hline & $\begin{array}{l}\text { Risks induced by terrorism } \\
{[35]}\end{array}$ & \\
\hline \multirow{4}{*}{ 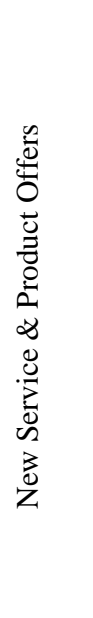 } & $\begin{array}{l}\text { Fee-based advisory } \\
\text { services will gain [3] }\end{array}$ & $\begin{array}{l}\text { "If the customer has a fire and needs to interrupt } \\
\text { operations, somebody comes and does not just } \\
\text { consult about the insurance but also about how to } \\
\text { make the company safe. Also for private persons" } \\
\text { (INSURANCE1) }\end{array}$ \\
\hline & $\begin{array}{l}\text { Change of sold service: } \\
\text { Awareness of prevention as } \\
\text { an alternative to remedying } \\
\text { [3] }\end{array}$ & $\begin{array}{l}\text { "Consulting [...] what you can do before the } \\
\text { damage occurs" (INSURANCE1) }\end{array}$ \\
\hline & $\begin{array}{l}\text { Growth opportunities e.g. } \\
\text { with capital financed } \\
\text { retirement products [3] }\end{array}$ & \\
\hline & & $\begin{array}{l}\text { Emerging markets need different services and } \\
\text { products (INSURANCE3b) }\end{array}$ \\
\hline
\end{tabular}


Method Support of Large-Scale Transformation in the Insurance Sector: Exploring

Foundations 9

\begin{tabular}{|c|c|c|}
\hline \multirow{6}{*}{ 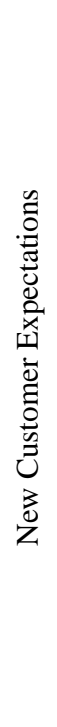 } & $\begin{array}{l}\text { Changing } \\
\text { behavior [3] }\end{array}$ & $\begin{array}{l}\text { Customer retention and customer relationships } \\
\text { become important (INSURANCE2). } \\
\text { Products need to be offered that flexibly adapt to } \\
\text { customer's life situation (INSURANCE3b). }\end{array}$ \\
\hline & $\begin{array}{l}\text { Increasing focus on more } \\
\text { differentiated target groups } \\
{[3]}\end{array}$ & \\
\hline & $\begin{array}{l}\text { Individualization } \& \\
\text { Personal marketing is very } \\
\text { important [3] }\end{array}$ & \\
\hline & $\begin{array}{ll}\text { Multi-channel } & \text { sales } \\
\text { necessary [3] } & \end{array}$ & \\
\hline & & $\begin{array}{l}\text { Social media as new contact channel } \\
\text { (INSURANCE3b) }\end{array}$ \\
\hline & & $\begin{array}{l}\text { Demographic change imposes challenges } \\
\text { (INSURANCE3b) }\end{array}$ \\
\hline \multirow{4}{*}{$\begin{array}{l}0 \\
\tilde{0} \\
0 \\
0 \\
0 \\
0 \\
0 \\
0 \\
0 \\
0 \\
0 \\
0 \\
0 \\
0 \\
0\end{array}$} & $\begin{array}{l}\text { Lower willingness to pay } \\
\text { of customers [3] }\end{array}$ & $\begin{array}{l}\text { "Cost pressure - people compare, if too many costs } \\
\text { are displayed" (INSURANCE1) } \\
\text { Costs need to be reduced (INSURANCE2) }\end{array}$ \\
\hline & $\begin{array}{l}\text { Banks as major competitors } \\
\text { [3] }\end{array}$ & \\
\hline & $\begin{array}{l}\text { Price more important than } \\
\text { brand [36] }\end{array}$ & \\
\hline & & $\begin{array}{l}\text { "Of course there are the deep market interests that } \\
\text { are apparent at the moment. The whole single life } \\
\text { and collective life business is no longer lucrative, } \\
\text { thus, new products are needed" (INSURANCE1) }\end{array}$ \\
\hline
\end{tabular}

Summarized, the evidence from the literature search was confirmed in the interviews. However, concerning the aspects of climate change and terrorisms induced risks, those were not mentioned in the interviews. We assume two reasons: First, handling risks is the core business of insurances [37], thus these new risks are not perceived as fundamental change but rather an evolution of the current core business model. Insurances developed a high maturity in dealing with such risks [3]. Some of those risks are difficult or impossible to insure anyway [38]. Second, our informants are located on managerial levels and less in the calculation of risks premiums. Concluding, we do not consider the environmental risks as a reason for ET further on. Summarized, we state the following proposition:

Proposition 1: Potential trigger for enterprise transformation programs are (1) regulation, (2) new service and product offers, (3) new customer expectations and (4) pressure to reduce costs. 


\subsection{Context of Enterprise Transformations}

ETs take place in a certain market and enterprise environment. The insurance market is rather stable concerning to the perceptions of our informants. Especially growth is not a primary goal of the insurance companies [3], e.g. since efficient distribution networks are already in place [39]. However, while not fostering growth in general, selecting the right customers is considered crucial. As an example, our informant from INSURANCE1 explained, that customers are classified into A, B, C and D categories. A-customers a treated with a special high service quality, meanwhile D customers the insurance tries to even get rid of. The insurance that handles the classification of customers in A to D classes in the best manner, will gain the best market revenues.

ET programs are strongly challenged by the availability of resources. Insurances are tackled by an inability to get access to qualified workers [3]. That leads to problems in the programs. While money is not considered to be a major problem, resource scarcity is crucial. Key persons in a program that have know-how are crucial for the success need to be kept in the program from beginning to end and should not be taken away by other programs.

The organizational structure usually is functional or organized in divisions. According to our informants, process oriented organizational structures are appearing more and more. The understanding about the extent of ETs in the insurances is almost the same like in general literature [1]. In INSURANCE1 the first discussed ET program affected three departments; the second discussed program affected seven departments. In INSURANCE2 the program affected also the whole organization. In INSURANCE3a the ETs affected the whole division in the area of IT or strategic development.

A low willingness to innovate that literature reveals [3] could not be confirmed by our informants. At least in the last time, product innovation or the need to change modes of working is seen in the insurances. INSURANCE2 and INSURANCE3 for example introduced new insurance products that in one case combined insurance with financial products; INSURANCE1 shifted the focus of its products to prevention. Because of the long-time stable business model of insurances (INSURANCE3b), the need for such innovation however occurred later than in other industries.

Summarized, the context of the ET is determined by a stable market with surprisingly (compared to the saturated traditional market) low cost pressure, where the actors needed to innovate in in order to gain or keep market share. In such market, highly qualified personnel are key and challenges exist to attract those people. The organizational structures are rather traditional and functional (INSURANCE3b).

Proposition 2: The enterprise transformation context is determined by a rather stable market, resource scarcity concerning qualified personnel, traditional organizational structures. 


\subsection{Classes of Enterprise Transformations}

Based on Baumoel [16, 17] we identified five classes of ET programs that are illustrated in table 2 .

Table 2. ET Program Types (based on $[16,17]$ )

\begin{tabular}{ll}
\hline Program Type & Description \\
\hline $\begin{array}{l}\text { Business } \\
\text { Networking }\end{array}$ & $\begin{array}{l}\text { Programs of this type are about collaboration and communication } \\
\text { with customers, partners and the systematic extension of such } \\
\text { relations - e.g. in the context of value networks or division of labor/ } \\
\text { Specialization. }\end{array}$ \\
\hline Optimization & $\begin{array}{l}\text { These programs are about the reengineering of existent processes or } \\
\text { functions e.g. in order to achieve cost-savings, speed increases or } \\
\text { higher quality. }\end{array}$ \\
\hline Roll Out & $\begin{array}{l}\text { Programs that incorporate new ideas that were developed in single } \\
\text { units or processes and transfer them to the whole organization or }\end{array}$ \\
\hline Repositioning & These programs are about change or extension of the strategy \\
\hline Flexibility Increase & $\begin{array}{l}\text { Programs of this type deal with increasing the entrepreneurial } \\
\text { capacity to act. }\end{array}$ \\
\hline
\end{tabular}

According to all informants, these categories cover most of the conducted ET programs. However, many programs could be related to more than one class (INSURANCE3b). The "roll out" class was considered to be rather incremental than fundamental change by one informant (INSURANCE3b). Summarized, this leads to proposition 3a:

Proposition 3a: The stated classes business networking, optimization, roll out, repositioning and flexibility increase cover most of the enterprise transformation programs conducted in insurance companies but not in a one-to-one manner.

However, the "repositioning" class of programs was perceived as very generic and almost a cover for the others by one informant (INSURANCE1). Further the question occurred, where to put standardization programs and programs that deal with the internal alignment of processes and information. The latter was brought up concerning the situation that it is often not clear, where relevant information can be found. An example is a claim that comes in and is of course assigned to a certain name. Nevertheless, it is not a simple task to collect all information and contracts about that person in order to provide a good service. The question is not that much how to connect these information sources technically but at first to investigate, who keeps the information where in the company (INSURANCE3a). Further it was not clear to the informants, were to put programs that deal with mergers and acquisitions (INSURANCE3b). This leads to proposition 3b: 
Proposition 3b: Programs that deal with standardization, internal alignment or mergers \& acquisitions are not properly covered by the presented classes.

We were interested, if drivers discussed above primarily foster programs of specific classes. The informants agreed that drivers can foster basically all of the above program classes. Nonetheless, some tendency is observable that certain drivers rather relate to certain program classes. For example, the pressure to reduce costs leads mainly to optimization programs. Regulation enforces on the one hand optimization but also the establishment of new ideas, since existing ones no longer are permitted. The informant of INSURANCE3b argued that optimized processes can better cope with new regulatory challenges. In INSURANCE1 the necessary new service \& product offers lead to cross-linking programs in order to include partners for the service provision. For example in the car insurance, INSURANCE1 works together with car garages in order to provide innovative services. The pressure for cost reductions goes along with optimization programs. Establishment is especially apparent when ideas from local agencies should be transferred to the market in other countries and thus also mostly driven by the need to introduce innovative services and products. Similar the informant from INSURANCE3b mentioned the transfer of bestpractices from mature to emergent markets. This leads to proposition $3 \mathrm{c}$ :

Proposition 3c: There seems to be a tendency that certain triggers relate to certain types of programs.

\subsection{Techniques of Enterprise Transformations}

Manifold techniques need to be applied in an ET program/effort/initiative, however, not all are necessary for each type of ET effort. With our informants we discussed the basis class of necessary techniques according to Baumoel $[16,17]$. The author claims that this list contains the techniques that should be applied in order to conduct successful ETs. We discussed this list with our informants in order to gain insights about the relevance and prioritization of the items. Most of the techniques were considered important in general. Table 3 shows the techniques that the informants considered especially important. 
Method Support of Large-Scale Transformation in the Insurance Sector: Exploring

Foundations 13

Table 3. Basic ET Techniques Considered especially Important

\begin{tabular}{|c|c|}
\hline Technique & Comments \\
\hline $\begin{array}{l}\text { Analysis of the expectations of the } \\
\text { involved persons }\end{array}$ & $\begin{array}{l}\text { "Very important, if this is not done it can } \\
\text { become very difficult" (INSURANCE1) } \\
\text { Important to be defined (INSURANCE2) }\end{array}$ \\
\hline $\begin{array}{l}\text { Analysis and definition of decision } \\
\text { processes }\end{array}$ & "Is done and is important" (INSURANCE1) \\
\hline Analysis and definition of the benefit & $\begin{array}{l}\text { Important to get commitment (INSURANCE2) } \\
\text { "No matter if the benefit is qualitative or } \\
\text { quantitative that needs to be done in order to } \\
\text { have measurable goals" (INSURANCE3b) }\end{array}$ \\
\hline Definition of the addressees of the ET & $\begin{array}{l}\text { "I would consider that as very important in } \\
\text { order to include the right parties in the change } \\
\text { process" (INSURANNCE3b) }\end{array}$ \\
\hline Definition of program goals & $\begin{array}{l}\text { "Very important, especially combined with } 18 \\
\text { [Analysis and definition of the benefit]" }\end{array}$ \\
\hline Definition of vision and mission & $\begin{array}{l}\text { "It is crucial, it is a communication tool" } \\
\text { (INSURANCE1) }\end{array}$ \\
\hline Definition of the program extent & $\begin{array}{l}\text { "Very very difficult, especially in large scale } \\
\text { projects, the tends to extent the project }[\ldots] \\
\text { Control of the extent is a very crucial factor" } \\
\text { (INSURANCE3b) }\end{array}$ \\
\hline \multirow[t]{2}{*}{$\begin{array}{l}\text { Definition and planning of the kind of } \\
\text { communication }\end{array}$} & $\begin{array}{l}\text { "Crucial, if it is not done, it becomes really } \\
\text { difficult" (INSURANCE1) }\end{array}$ \\
\hline & $\begin{array}{l}\text { "Communication is extremely crucial," } \\
\text { (INSURANCE3b) }\end{array}$ \\
\hline $\begin{array}{l}\text { Determination of stakeholder } \\
\text { influences }\end{array}$ & $\begin{array}{l}\text { It is important to identify the interests of all the } \\
\text { stakeholders (INSURANCE3b). }\end{array}$ \\
\hline $\begin{array}{l}\text { Guidance: Ensure management } \\
\text { commitment and role model }\end{array}$ & $\begin{array}{l}\text { "Absolut crucial" (INSURANCE1) } \\
\text { "Absolutely crucial - } \\
\text { sponsorship, commitment, } \\
\text { (INSURANCE3b) }\end{array}$ \\
\hline
\end{tabular}

The analysis of the expectations of involved persons as much as the definition and analysis of the benefits was perceived as very important by almost all informants. Further the important role of communication was highlighted. It became apparent that especially techniques that are emphasized in traditional management literature are perceived as very important. The aspect of management attention was highlighted a lot by the informants, even if the extend may differ. For INSURANCE1, management attention is true buy in and commitment which is reflected by being involved in steering boards and active control with not just one but many managers. The informant from INSURANCE3a highlighted that from an IT perspective not 
necessarily management attention is the key success factor but attention from the business side.

Summarized, the general techniques stated to be important for every ET mostly apply for the insurance industry, too. There was no technique that all informants consider to be relevant, however some were perceived as being especially important. Some were perceived to cover the same issue and could be condensed in a single item.

Proposition 4a: The provided list of basic techniques in general is relevant for enterprise transformation programs in the insurance sector. Some basic techniques seem to be more important than others.

Some of the techniques in the list have been considered redundant or including each other. Our informant from INSURANCE1 for example would not cover the analysis of consequences in an additional point since such argumentation should be covered in the goals. Explicit analysis of the consequences is not seen as a necessary technique to achieve program success.

For certain techniques, the informants differed in their view. For example our informant from INSURANCE3a considered the technique of defining a vision for the ET as not necessary or even not appropriate. For him, the vision belongs to the corporate level but not to the level of ET programs, in here goals are the relevant aspect. The other informants however, considered having a vision as especially important.

We also asked the informants about techniques they would not consider as absolutely crucial or less important. Table 4 summarizes this discussion.

Table 4. Basic ET Techniques often not Conducted or not Considered to be Crucial

\begin{tabular}{ll}
\hline Technique & Comments \\
\hline Analysis of the dominant corporate cultures & "Never saw that this was done $[\ldots]$ \\
and subcultures & you would rather think about how to \\
& influence the culture in order to \\
& realize the strategy" \\
& (INSURANCE1) \\
\hline
\end{tabular}


Method Support of Large-Scale Transformation in the Insurance Sector: Exploring

Foundations 15

\begin{tabular}{ll}
\hline Analysis of the history of success & "Never seen, there are success stories \\
but not because of a project" & (INSURANCE1) \\
& "We maybe do that not enough, we \\
document the findings in the project & but we might not have the maturity \\
& achieved in that area to analyze it \\
before each new project" & (INSURANCE3a) \\
\hline Analysis of the mentality / mindset & "Done rather seldom but might be \\
& more important to do" \\
& (INSURANCE1) \\
"That is not done" (INSURANCE3b)
\end{tabular}

It becomes apparent that many of the techniques that were described as less important or less used, deal with rather "soft" factors. An explanation might be the hierarchical culture in the industry that shifts concentration rather to the "hard" techniques. However, incorporating these factors might be a good idea in order to increase the success probability of the ET.

Proposition 4b: Techniques that deal with "soft" aspects are less used and considered to be less crucial than "hard" ones. 


\section{Discussion}

ETs are a relevant topic in the insurance industry, motivated by different aspects. We identified detailed context, triggers, program types and core techniques that are relevant. In table 5 we summarize the propositions we derived within the findings section.

Table 5. Propositions Summary

\begin{tabular}{ll}
\hline & Proposition \\
\hline 1 & $\begin{array}{l}\text { Potential trigger for enterprise transformation programs are (1) regulation, (2) new } \\
\text { service and product offers, (3) new customer expectations and (4) pressure to reduce } \\
\text { costs. }\end{array}$ \\
\hline 2 & $\begin{array}{l}\text { The enterprise transformation context is determined by a rather stable market, resource } \\
\text { scarcity concerning qualified personnel, traditional organizational structures. }\end{array}$ \\
\hline $3 \mathrm{a}$ & $\begin{array}{l}\text { The stated classes business networking, optimization, roll out, repositioning and } \\
\text { flexibility increase cover most of the enterprise transformation programs conducted in }\end{array}$ \\
& insurance companies but not in a one-to-one manner. \\
\hline $3 \mathrm{~b}$ & $\begin{array}{l}\text { Programs that deal with standardization, internal alignment or mergers \& acquisitions } \\
\text { are not properly covered by the presented classes. }\end{array}$ \\
\hline $3 \mathrm{c}$ & There seems to be a tendency that certain triggers relate to certain types of programs. \\
\hline $4 \mathrm{a}$ & $\begin{array}{l}\text { The provided list of basic techniques in general is relevant for enterprise } \\
\text { transformation programs in the insurance sector. Some basic techniques seem to be } \\
\text { more important than others. }\end{array}$ \\
\hline $4 \mathrm{~b}$ & $\begin{array}{l}\text { Techniques that deal with "soft" aspects are less used and considered to be less crucial } \\
\text { than "hard" ones. }\end{array}$ \\
\hline
\end{tabular}

Based on proposition 3c, we identified a first mapping of triggers and program types in the insurance context (see illustration in figure 2). We thus extended the Baumoel $[16,17]$ approach with this part. We identified four classes of potential triggers for ET programs, such as regulation, new service and product offers, new customer expectations and the pressure to reduce costs. These are especially triggers, because the insurance market is rather traditional business (INSURANCE3b), in other markets and branches the triggers might be different or less foster fundamental change. We gained evidence that certain triggers can be mapped to certain program types - this allows to (1) better communicate the necessary ET steps and (2) shows that the existent categories are suitable also for the insurance industry. However, the discussions showed that some programs are not clearly covered or hard to fit in the program classes. For those programs, further research about their guidance is necessary. This is especially the case, since the issue was not just mentioned by one informant but across the different cases. Furthermore, IT related programs seem to have additional needs concerning the applied techniques. No longer management attention but rather attention from the business side was considered to be very 
important (INSURANCE3a). To cover this, we would extend the approach by a class of techniques especially needed for IT programs.

We further could identify techniques that our informants consider to be more or less important for ETs in the insurance sector (see tables 3 and 4 in the results section). ETs are affected by the hierarchical structures that most insurance companies persist of. Evidence for that is provided by the perceived minor relevance of techniques like analysis of mentality, etc. Because of the hierarchical coordination, such aspects might not be considered to be important. However, when it comes to the movement to new emergent markets, those techniques might gain in importance. We would thus propose, to cover this by a class of programs that especially deals with addressing new emergent markets.

Our initial assumption that the insurance context fosters different classes of techniques or prioritizations partially holds true. However, almost all informants did not see specifics to other companies from the financial industry (e.g. banks) since e.g. factors like regulation are also given here. We therefore see a huge potential in increasing the industry context to the financial industry as such. Figure 2 illustrates the findings, proposition $3 \mathrm{c}$ is included by the mapping arrows; the context is illustrated by the grey background.

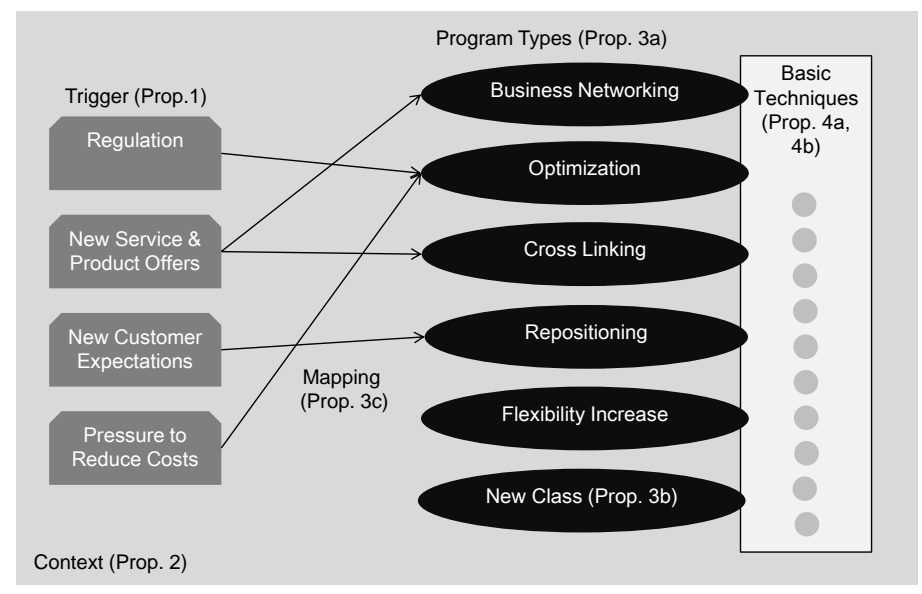

Fig. 2. Summarized Overview

\section{Summary \& Outlook}

In this article we explored context, trigger, ET situation and core technique candidates for the insurance sector. The focus on insurances helps to focus scarce resources on the most promising aspects for ET success. We further identified connection points for further research.

However, the chosen research design implies some limitations. We used a given method for the guidance of ET as a foundation for our work. That implies the following major weakness: A certain bias exists, which classes and techniques exist 
and might be important. We covered this problem by applying a qualitative research design that allows for deeper discussion than a quantitative evaluation of the techniques. A quantitative approach would have not allowed us to determine that some ETs are difficult to cover with the existing situations and especially which ones not. Another limitation that occurs is about biases of informants. Even if we used methods that avoid such biases, e.g. we cannot be sure that if informants perceive an ET as successful, such ET is also successful in the scientific sense. We further did not conduct an evaluation of the findings presented in the paper so far. However, the chosen approach is well-known for the characteristic of providing stable empirical propositions.

The topic is very complex we were only able to cover a very broad rather than a deep perspective in this paper. However, we gained insights into the context, triggers, program types and core techniques in order to prioritize further in-depth work. The paper at hand is especially important to identify the foundations for the development of usable artifacts in the future. Thus the paper at hand has to be considered as a first exploration of the field, while further more detailed analysis and afterwards design steps will follow. This includes e.g. validation of the interviews by means of a survey and single in-depth case studies including an analysis and evaluation of the adopted methods.

\section{References}

1. $\quad$ Rouse, W.B.: A Theory of Enterprise Transformation. Systems Engineering 8:4, 279295 (2005)

2. Ward, J., Uhl, A.: Success and Failure in Transformation - Lessons from 13 Case Studies. $360^{\circ}$ - The Business Transformation Journal:3, 30-38 (2012)

3. Fuernthaler, A., Baettig, V., Burr, B., Stampfli, C.: Insurance in 2015 - Determining the Position: New Coordinates in the German-speaking Insurance Market. (2010)

4. Trichet, J.C.: Financial stability and the insurance sector. Geneva Papers on Risk and Insurance-Issues and Practice 30:1, 65-71 (2005)

5. Giordano, G., Lamy, A., Janasz, T.: Who's the Leader? Financial IT Integration at a Global Insurance Company. $360^{\circ}$ - The Business Transformation Journal:1, 53-59 (2011)

6. Hawawini, G., Subramanian, V., Verdin, P.: Is performance driven by industry-or firm-specific factors? A new look at the evidence. Strategic Management Journal 24:1, 1-16 (2003)

7. Becker, J., Pfeiffer, D., Räckers, M., and Fuchs, P.: Business Process Management in Public Administrations - The PICTRUE Approach. (2007)

8. Bucher, T., Klesse, M., Kurpjuweit, S., Winter, R.: Situational Method Engineering On the Differentiation of "Context" and "Project Type". In: Situational Method Engineering - Fundamentals and Experiences, pp. 33-48. Springer, Geneva (2007)

9. Lahrmann, G., Winter, R., Fischer, M.: Design and Engineering for Situational Transformation. In: Practice-Driven Research on Enterprise Transformation, pp. 116. Springer, Delft, The Netherlands (2010) 
10. Winter, R.: Design Solution Analysis for the Construction of Situational Design Methods. Engineering Methods in the Service-Oriented Context 351, 19-33 (2011)

11. Powell, T.C.: Total quality management as competitive advantage: a review and empirical study. Strategic Management Journal 16:1, 15-38 (1995)

12. Linderman, K., Schroeder, R.G., Zaheer, S., Choo, A.S.: Six Sigma - A GoalTheoretic Perspective. Journal of Operations Management 21:2, 193-203 (2003)

13. Goh, T.N.: Six Triumphs and Six Tragedies of Six Sigma. Quality Engineering 22:4, 299-305 (2010)

14. Österle, H., Winter, R.: Business Engineering. In: Österle, H., Winter, R. (eds.): Business Engineering - Auf dem Weg zum Unternehmen des Informationszeitalters, pp. 3-19. Springer, Berlin etc. (2003)

15. Stiles, P., Uhl, A.: Meta Management: Connecting the Parts of Business Transformation. $360^{\circ}$ - The Business Transformation Journal:3, 24-29 (2012)

16. Baumöl, U.: Strategic Agility through Situational Method Construction. In: Reichwald, R., Huff, A.S. (eds.): Proceedings of the European Academy of Management Annual Conference 2005, pp. 1-34 (2005)

17. Baumöl, U.: Change Management in Organisationen: Situative Methodenkonstruktion für flexible Veränderungsprozesse. Gabler, Wiesbaden (2008)

18. Teece, D.J.: Explicating dynamic capabilities: the nature and microfoundations of (sustainable) enterprise performance. Strategic Management Journal 28:13, 13191350 (2007)

19. Beer, M.: The transformation of the human resource function: Resolving the tension between a traditional administrative and a new strategic role. Human Resource Management 36:1, 49-57 (1997)

20. Van Helden, G.J.: Researching Public Sector Transformation: The Role of Management Accounting. Financial Accountability \& Management 21:1, 99-133 (2005)

21. Harmsen, F., Proper, E., Kok, N.: Informed Governance of Enterprise Transformations. In: Proper, E., Harmsen, F., Dietz, J.L.G. (eds.): Advances in Enterprise Engineering II, pp. 155-180. Springer, Berlin Heidelberg (2009)

22. Purchase, V., Parry, G., Valerdi, R., Nightingale, D., Mills, J.: Enterprise Transformation: Why Are We Interested, What Is It, and What Are the Challenges? Journal of Enterprise Transformation 1:1, 14-33 (2011)

23. Staw, B.M., Epstein, L.D.: What Bandwagons Bring: Effects of Popular Management Techniques on Corporate Performance, Reputation, and CEO Pay. Administrative Science Quarterly 45:3, 523-556 (2000)

24. Iseri-Say, A., Toker, A., Kantur, D.: Do popular management techniques improve performance?: Evidence from large businesses in Turkey. Journal of Management Development 27:7, 660-667 (2008)

25. Eisenhardt, K.M.: Building Theories from Case Study Research. Academy Of Management Review 14:4, 532-550 (1989)

26. Eisenhardt, K.M., Graebner, M.E.: Theory Building from Cases: Opportunities and Challenges. Academy Of Management Journal 50:1, 25-32 (2007)

27. vom Brocke, J., Simons, A., Niehaves, B., Riemer, K., Plattfaut, R., Cleven, A.: Reconstructing the Giant: On the Importance of Rigour in Documenting the 
Literature Search Process. In: Proceedings of the ECIS 2009, pp. 2206-2217, Verona (2009)

28. Webster, J., Watson, R.T.: Analyzing the Past to prepare for the Future: Writing a Literature Review. MIS Quarterly 26:2, 13-23 (2002)

29. Huber, G.P., Power, D.J.: Retrospective reports of strategic-level managers: Guidelines for increasing their accuracy. Strategic Management Journal 6:2, 171-180 (1985)

30. Burke, L.A., Miller, M.K.: Phone Interviewing as a Means of Data Collection: Lessons Learned and Practical Recommendations. Forum: Qualitative Social Research 2:2, 1-8 (2001)

31. Jick, T.D.: Mixing Qualitative and Quantitative Methods: Triangulation in Action. Administrative Science Quarterly 24:4, 602-611 (1979)

32. Noy, C.: Sampling Knowledge: The Hermeneutics of Snowball Sampling in Qualitative Research. International Journal of Social Research Methodology 11:4, 327-344 (2007)

33. Phelan, L., Taplin, R., Henderson-Sellers, A., Albrecht, G.: Ecological Viability or Liability? Insurance System Responses to Climate Risk. Environmental Policy and Governance 21:2, 112-130 (2011)

34. Thistlethwaite, J.: The ClimateWise Principles: Self-Regulating Climate Change Risks in the Insurance Sector. Business \& Society 51:1, 212-147 (2012)

35. Wolgast, M.: Global terrorism and the insurance industry: new challenges and policy responses. In: Brueck, T. (ed.): The Economic Analysis of Terrorism, pp. 146-172. Routledge, Abington (2007)

36. Van Dijk, M., Pomp, M., Douven, R., Laske-Aldershof, T., Schut, E., De Boer, W., De Boo, A.: Consumer price sensitivity in Dutch health insurance. International Journal of Health Care Finance \& Economics 8:4, 225-244 (2008)

37. Thoyts, R.: Insurance Theory and Practice. Routledge, Abington (2010)

38. Jaffee, D.M., Russell, T.: Catastrophe Insurance, Capital Markets, and Uninsurable Risks. The Journal of Risk and Insurance 64:2, 205-230 (1997)

39. Kling, G., Ghobadian, A., O'Regan, N.: Organic growth and shareholder value: A case study of the insurance industry. International Journal of Research in Marketing $27: 4,276-283$ (2009) 